\title{
Fuzzy cognitive mapping of Baltic Archipelago Sea food webs reveals no cliqued views of the system structure between stakeholder groups
}

\author{
Laura Uusitalo ${ }^{1}$, Susanna Jernberg ${ }^{1}$, Patrik Korn ${ }^{1}$, Riikka Puntila-Dodd ${ }^{1}$, Annaliina Skyttä ${ }^{1}$, Suvi Vikström ${ }^{1}$ \\ ${ }^{1}$ Finnish Environment Institute, Helsinki, Finland
}

\begin{abstract}
Incorporating stakeholder views is a key element in successful environmental management, particularly if the managed system delivers cultural and provisioning ecosystem services directly to the stakeholders, or if there are conflicting views about the ecosystem functioning or its optimal management. One such system is the Archipelago Sea in the Southwestern coast of Finland. It is an area with high biodiversity, offering a range of ecosystem services, from regulating services to provisioning and cultural services. Furthermore, it is subjected to a variety of human activities ranging from eutrophication and marine transport to fishing. The management of the area is also a topic of debate, including discussions of minimum landing size of fish, seal hunting quotas, and the role of cormorants in the ecosystem. Fuzzy cognitive mapping offers a method to evaluate and quantitatively compare different actors' views on ecosystem structure. The models can be compared quantitatively and simulated to illustrate how they respond to various pressure scenarios. This may reveal differences in the perceptions about what are the important interactions in the ecosystem, and how the system would respond to management measures, potentially explaining differing opinions about the best management strategy. In this work, 30 stakeholders, including policy makers, scientists, eNGOs, fisheries, and recreational users created fuzzy cognitive maps (FCMs) of the Archipelago Sea food web. We found that despite the debate about the management of the area, the stakeholders' views about the food web structure were not clustered based on the stakeholder group, i.e. the different stakeholder groups did not have distinct ideas about the ecosystem structure. The FCM complexity did not show a pattern based on the stakeholder group either. While the general pattern of the FCMs indicated a shared view of the food web structure across most respondents, there was one map from the recreational group that stood out. The exact setup of the models varied. Across all maps, cod, perch, fishing, zooplankton, and herring were the variables having most links with the other variables. The simulated ecosystem responses indicated that fishing was seen as a key factor affecting food web components, while increases of salinity and oxygen levels have a positive impact on multiple ecosystem components. The value of the approach is to enable a two-way discussion about the food webs and how management of pressures may impact the components.
\end{abstract}

\section{Keywords}

Fuzzy Cognitive mapping; food web; Archipelago Sea; management; stakeholder interaction

\section{Code availability}

The analyses were run in R computing environment. The encoded maps and the R code for the analysis and visualization are available at https://github.com/luusitalo/FCM AS.

\author{
Correspondence: \\ Contact L. Uusitalo at Laura.Uusitalo@ymparisto.fi \\ Cite this article as: \\ Uusitalo, L., Jernberg, S., Korn, P., Puntila, R., Skyttä, A., \& Vikström, S. \\ Fuzzy cognitive mapping of Baltic Archipelago Sea food webs reveals no cliqued views of the system \\ structure between stakeholder groups \\ Socio-Environmental Systems Modelling, vol. 2, 16343, 2020, doi:10.18174/sesmo.2020a16343
}

This work is licensed under a Creative Commons Attribution-NonCommercial 4.0 International License. 


\section{Introduction}

Today, incorporating stakeholder views is identified as a key element in successful environmental management, particularly if the managed system delivers cultural and provisioning ecosystem services directly enjoyed by the stakeholders (Chan et al., 2012; Pahl-Wostl et al., 2007). In cases of varying opinions about the best management strategies, the disagreements may stem not only from differing values (which aspects of the ecosystem, and ecosystem services, are appreciated the most), but also from difference in understanding of the ecosystem dynamics, i.e. what are the expected consequences of the proposed management actions. In order to implement effective and socially acceptable environmental management, it is important to understand and analyze these factors.

Fuzzy cognitive mapping provides a tool for mapping and quantitatively analyzing stakeholders' views about a system's structure (Jetter \& Kok, 2014; Sluis et al., 2019; Vasslides \& Jensen, 2016), and they have been used to include stakeholders in ecological (Özesmi \& Özesmi, 2004; Solana-Gutiérrez et al., 2017) and socio-ecological (Game et al., 2018; Giabbanelli et al., 2017; Pacilly et al., 2016) research. They are particularly useful when attempting to illustrate the impacts of various pressures in a complex ecosystem or food web setting (Hobbs et al., 2002). The maps can be compared, clustered, and simulated to see how the system would react to different changes in the pressures according to each map (Kontogianni et al., 2012). A fuzzy cognitive map (FCM) (Kosko, $1986)$ is a graphical and mathematical representation of a specific system's structure, according to the person who constructed the map (Stier et al., 2017). FCMs are constructed by connecting variables (also called concepts) with arrows to represent the relationships and interactions between the variables (Özesmi \& Özesmi, 2004; Stier et al., 2017). Interaction type and strength are indicated by numbers showing the interaction strength and whether it is positive or negative. A positive interaction indicates that a concept increases another concept, whereas a negative interaction indicates that a concept decreases another concept (Jetter \& Kok, 2014; Özesmi \& Özesmi, 2004).

The Archipelago Sea is a large coastal area in the southwestern coast of Finland, which comprises more than 40000 islands and skerries, and hosts ecologically important areas (Virtanen et al., 2018). The whole area is intensively used by humans (Leppäkoski et al., 1999) and its sociocultural value has been recognized as its part of UNESCO's Man and Biosphere programme. The anthropogenic activities and pressures include nutrient loading from rivers, agriculture, and fish farming, ship traffic, boating, and alteration of habitats (Leppäkoski et al., 1999), as well as impacts of invasive species (Kraufvelin et al., 2018). The Archipelago Sea is economically important for both the commercial and recreational fisheries, as well as other recreational activities (e.g. water sports and tourism), and hence supports a variety of ecosystem services (Viirret et al., 2019). The area has also undergone changes especially in past decades: the abundance of seals (Harding and Härkönen, 1999; Kauhala et al., 2019) and cormorants (Salmi et al., 2015) have recovered after being largely absent for decades; and several new non-indigenous species have arrived (Kraufvelin et al., 2018). Due to a large and variable pool of users in the area, the views of good management are variable. The increase in cormorant abundance appears to be especially divisive (Hansson et al., 2018a, 2018b; Heikinheimo et al., 2018).

The aim of this work was to analyse stakeholders' views of the Archipelago Sea marine food web. The aim was to see how much variation there is among the views, and whether the views of the ecosystem structure are clustered based on the stakeholder group, i.e. whether the views are more similar within a stakeholder group than between them. Further, we wanted to analyze how the stakeholders' mental models respond to different pressures such as climate change and different nutrient loading and fishing scenarios. These models' simulations could explain the stakeholders' management preferences, as they illustrate how strongly different pressures are expected to affect the variables of interest.

\section{Methods}

\subsection{Stakeholder workshop and interviews}

To acquire fuzzy cognitive maps of the Archipelago Sea food web functioning from different stakeholder groups, over 30 personal invitations were sent out by email to selected stakeholders. The first batch of 7 stakeholders were invited to a workshop in Pargas, an archipelagic town in South West Finland in March 2018. Further 23 FCMs were obtained through individual interviews. These were held at a location chosen by the respondent 
(often either at their workplace or at the office of Finnish Environment Institute SYKE). 30 maps were acquired from 30 individuals, comprising 6 people from each of the following 5 stakeholder groups: Aquatic scientists, policy makers, environmental non-governmental organizations (eNGOs), people with professional fishery perspectives (professional fishers, their representatives, and local fishery managers), and people with recreational use perspectives (recreational users and a recreational fishing guide). These stakeholder groups were selected as their actions have a direct link to food web processes, unlike other stakeholder groups, such as the shipping industry, where influence is indirect. The individual stakeholders invited to represent these groups were selected based on their relevant role within these groups locally or nationally.

At the start of the workshop and each interview, FCMs were introduced using an example model (Figure 1) of a terrestrial food web FCM (Gray et al. 2012; Özesmi \& Özesmi 2004; Taber, 1991;). The participants were asked to "draw a map of the food web in the Archipelago Sea". To do this they wrote down variables (e.g. different species) on a piece of paper, and then indicated with the use of arrows who eats who or what kind of effect the variables had on each other. The strengths of the interactions were indicated to be strong, medium, or weak, with no link indicating no (or negligible) interaction. Whether the interactions were positive or negative was also indicated.

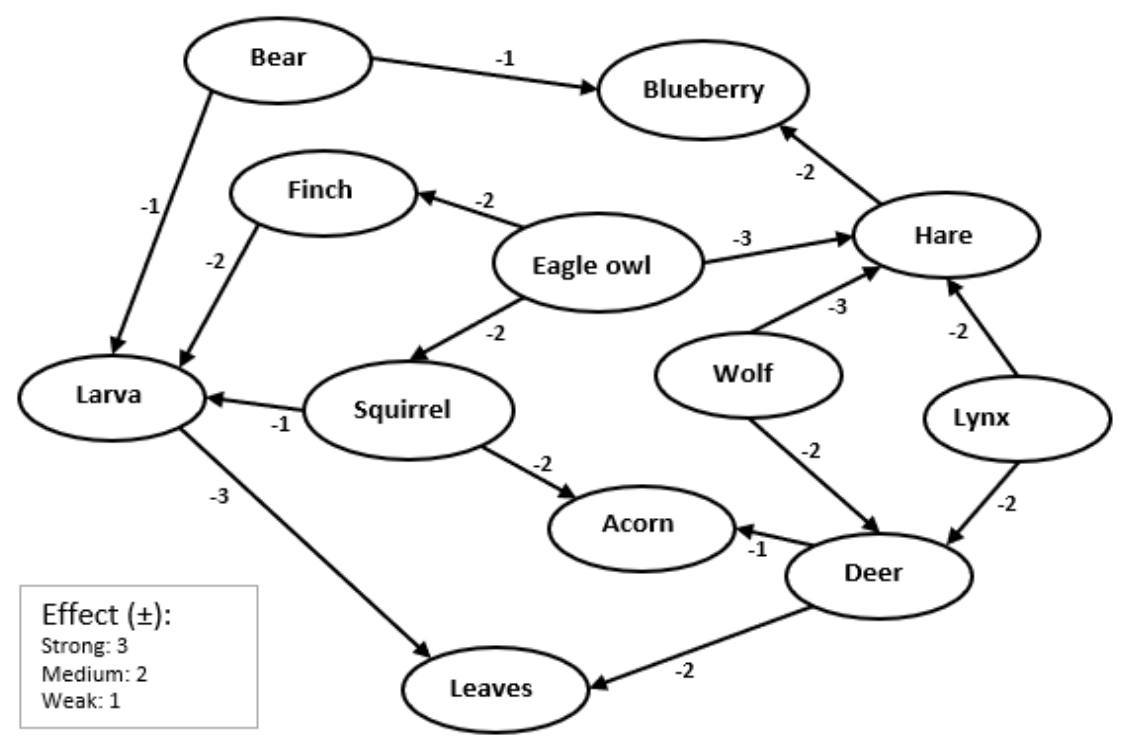

Figure 1: The example mental map that was given to the participants in the beginning of the interview.

The interviewees were given a list of 18 components (concepts) that they could use when building the FCM (Fairweather, 2010; Markóczy \& Goldberg, 1995) (Table 1). The interviewees were told that they could use the components on this list freely, and that they could also come up with their own components. The interviewees were told to include up to a maximum of 20 different variables in the model, meaning that if they used every given concept from Table 1, they could still add two more concepts to the FCM. This limit was set in order to harmonize the models; the limit for example discouraged the respondents from including all the individual plankton genera. Additionally, this limited the cognitive burden of the respondents and allowed more straightforward analysis of the results. The only request was that all external effects (temperature, salinity, oxygen, eutrophication, fishing) from the component list should be used. The direction of the effect was given in order to guarantee that the respondents used the plus and minus effects the same way, since the natural food web interaction directions do not directly apply here. The climate-related variables were based on the projections on the area (BACC II Author Team, 2015); and eutrophication and fishing were allowed to increase as this is expected to be cognitively easier (e.g., there are real life examples of the impacts of both). However, as the interactions are expected to be linear, via symmetry this model also allows for evaluation of the opposite development (i.e. decreases in fishing and eutrophication). The stakeholders were told that a good way to build the FCM could be by starting from cod, and building the model from there. This served as an icebreaker to make it easier to start the exercise, and as an anchor to harmonize the models' trophic level and the level of detail. 
No maximum time limit for making the FCMs was set, and the stakeholders were welcome to take as much time as they felt they needed. The FCMs were seen to be ready when the stakeholders no longer had anything to add to the system (Özesmi \& Özesmi 2004). The time it took for each stakeholder to complete the FCM varied, but rarely exceeded one hour. The stakeholders could ask any questions if and when they wanted.

Table 1: The proposed and required (marked with an asterisk) components of the FCMs.

\begin{tabular}{lll}
\hline Fish & Other & External effects* \\
\hline Cod & Phytoplankton & Temperature (increase)* \\
Zander & Zooplankton & Salinity (decrease)* \\
Baltic herring & Mammals & Oxygen (decrease)* \\
Sticklebacks & Birds & Eutrophication (increase)* \\
Flounder & Benthos & Fishing (increase)* \\
Perch & & \\
Pike & & \\
\hline
\end{tabular}

\subsection{Analyses}

Prior to quantitative analyses, the maps were harmonized in nomenclature, and in some cases edited slightly for higher comparability. For example, some maps included "roach", some both "roach" and "bream", and most of them simply "cyprinids". All of these were renamed and combined into "cyprinids" in order to retain the highest possible comparability between the maps. Although the guidance was to limit the amount of variables included in the FCMs to 20, this was not always the result. In the cases where the number of variables were greater than 20, some of the variables were merged together (if and where it made sense), to reach 20 (Jetter \& Kok 2014; Özesmi \& Özesmi 2004). From one map, one variable was removed ("Nutrient loading”, which was linked only to eutrophication), and in another map, 21 variables were left as none of these approaches were applicable. In two cases, FCMs without any numbers (weights) for interactions were received, but these included the interaction pathways (arrows) and the classification (negative or positive) of the interactions. In these two cases all the interaction strengths were assumed to be weak ( $1 / 3)$. This was a conservative assumption, as most of the links in the other models were weak. We tested the sensitivity of this assumption by changing all these links to strong, and while some of the results did change, the overall outcome in that instance didn't change the main results or conclusions of this work.

The maps were analyzed in R (R Core Team 2018) using the FCM package. For the quantitative analyses, the maps were converted to matrices, and the interaction strengths were transformed to be between 0 and 1 . Weak, medium and strong interactions became $1 / 3,2 / 3$, and 1 , respectively (Özesmi \& Özesmi 2003). For each map, the following metrics were recorded: the number of variables, the connection density (i.e. the proportion of the total possible links there are between the variables), and the centrality value of each variable (i.e. how many and how strong are links to and from each variable).

To allow similarity (or dissimilarity) comparisons between the FCMs, non-metric multidimensional scaling was used to evaluate the differences between the maps, and to see whether the maps by individuals in the same stakeholder groups are more similar to each other than to participants in different groups. This was done using the isoMDS function of the MASS R package (R Core Team, 2018; Venables \& Ripley, 2002). The multidimensional scaling was computed based both on variable centrality (i.e. the centrality value of each variable in each model) and based on the links between variables in each model (i.e. whether they had similar links between variables).

The FCMs were simulated to find the equilibrium value for each variable based on the interactions in the FCM. These simulations find a state in which the FCM is in balance, and each variable has an equilibrium value. Finally, the models were simulated while one variable at a time was fixed to have either the highest or lowest possible value $(1,-1)$. These simulations can lead to balance states and equilibrium values that differ from the base run, and they help shed light on what kind of changes the interviewees expect, given that these variables change as simulated. The differences of each of these scenarios were compared to the base case, to illustrate the difference the pressure makes in the system according to the maps. These differences were computed for simulations that included all the 30 maps, and for simulations of each stakeholder group's models separately. 


\section{Results}

The number of variables in the final maps varied between 10 and 21, and the connection density (the number of links divided by their highest possible number) between 9 and $28 \%$ of the highest possible number of links (where every variable is linked to every other variable) (Figure 2). There were no statistically significant differences between the stakeholder groups in either of these indices, but the variability within certain groups was high.
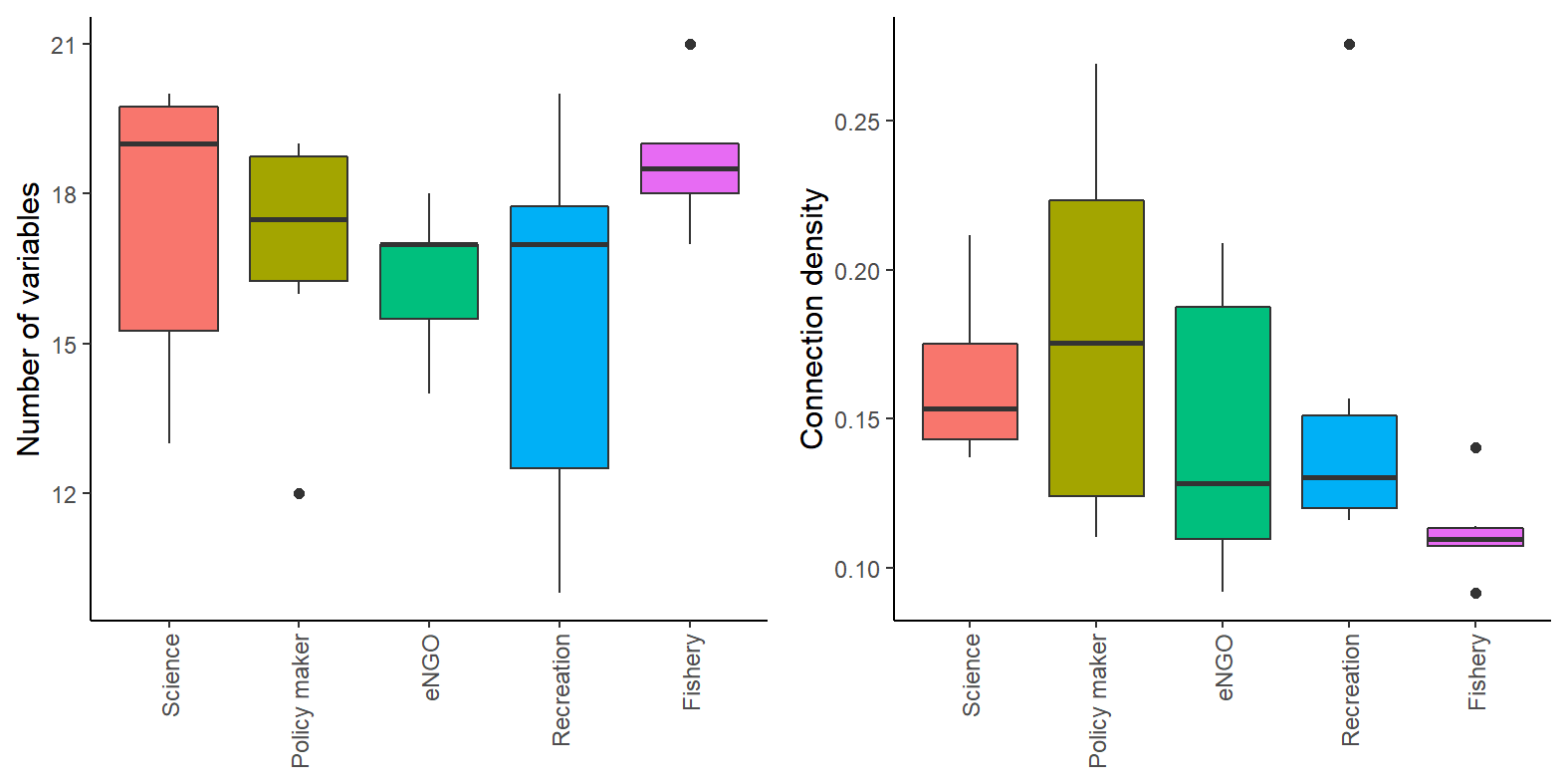

Number of variables and connection density of each map

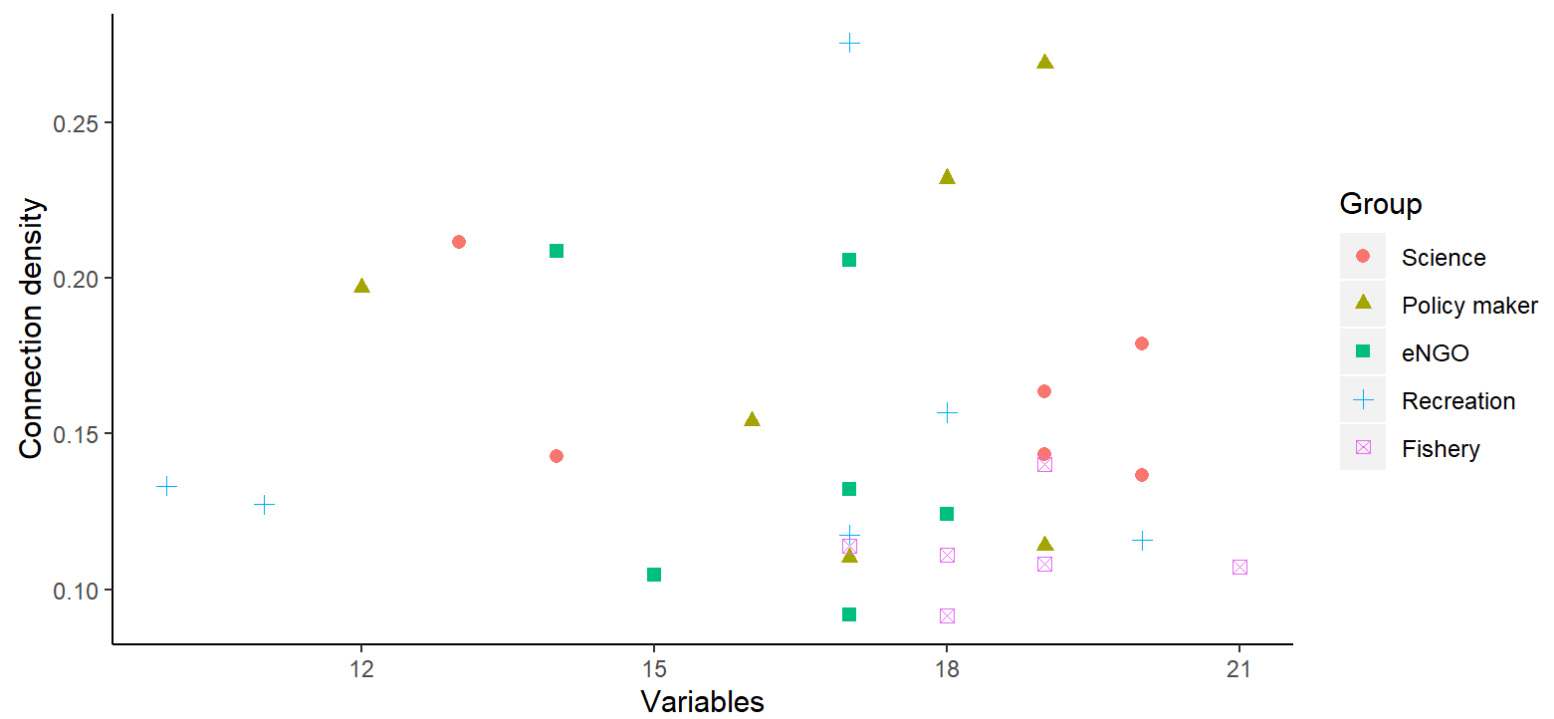

Figure 2: Distribution of the number of variables and the connection density within each stakeholder group.

Across all the maps, the most central variables were those 18 ecosystem components that were given in the indicative list (Figure 3a). However, 20 other variables were also mentioned in at least one of the maps, with the number of variables present in the models totaling 38. The most central variables, indicating how important the respondent thought the variable was, varied to some extent between the stakeholder groups, but the general pattern was very similar in all the groups (Figure $3 b-f)$. Cod, fishing, and eutrophication were the most central variables across all maps, but compared to the other groups, the recreation group considered eutrophication less important and the fishery professionals considered cod less important. 

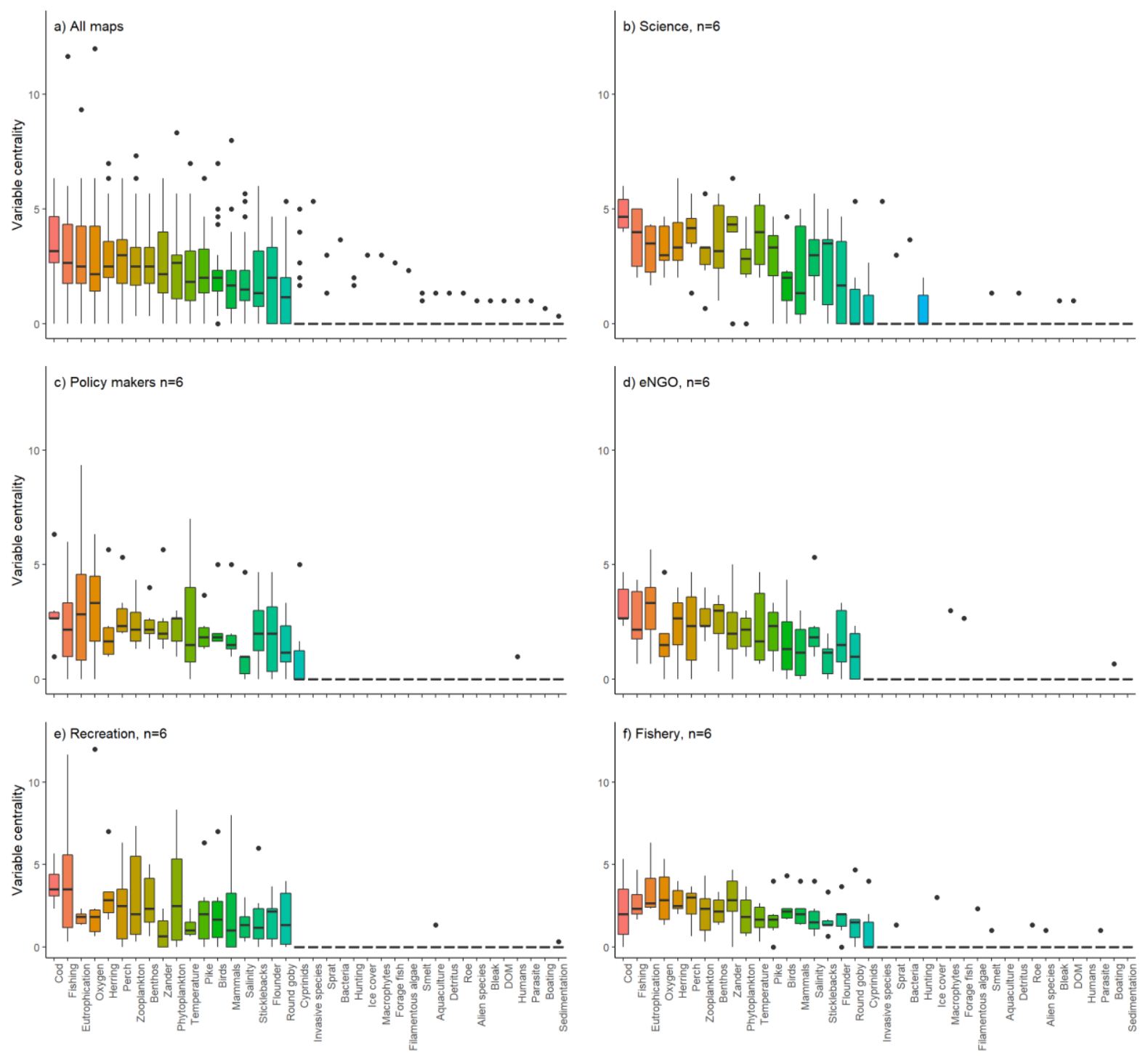

Figure 3: Variable centralities of a) all of the respondents, b)-f) divided by the stakeholder group. The variables are ordered by mean centrality across all respondents.

The maps did not cluster to stakeholder-specific groups in multidimensional scaling, when clustered either based on which variables were seen as the most central or based on which links existed in the models (Figure 4). The stress value, which describes the goodness of fit, was $12.0 \%$ and $18.7 \%$, indicating a fair fit. In the threedimensional solution (not shown), the stress levels dropped to $8.2 \%$ and $13.3 \%$, respectively.

The model simulations show how the concepts' (i.e. ecosystem components') balance states would change if the pressures were in the highest or lowest possible value. These simulations were run for all the maps jointly and for each stakeholder group separately; we show those scenarios that featured the largest changes, i.e. decreased fishing (Figure 5) and decreased eutrophication (Figure 6). The values in Figures 5 and 6 indicate the difference between each of the scenarios and the base run (where the pressures' values were not set). Values above zero indicate that the ecosystem component is expected to increase compared to the base state, and values below zero indicate that it is expected to decrease. In general the predictions were very similar across the groups, even though the effect strength varied. Some of the clear similarities include the belief that perch and zander will increase if fishery is increased, and phytoplankton will decrease if eutrophication is decreased. On the other hand the strongest differences lie in the predicted response of mammals and birds: under the decreased fishing scenario, the science group believe that mammals will increase and the recreation group believe both mammals and birds will increase, while the other groups don't predict any changes (Figure 5). Also, 
unlike the others, the fishery professionals do not see any differences in cod, if fishery is reduced. In the reduced eutrophication scenario, policy makers believe that birds will increase, while eNGOs believe that birds will decrease (Figure 6).
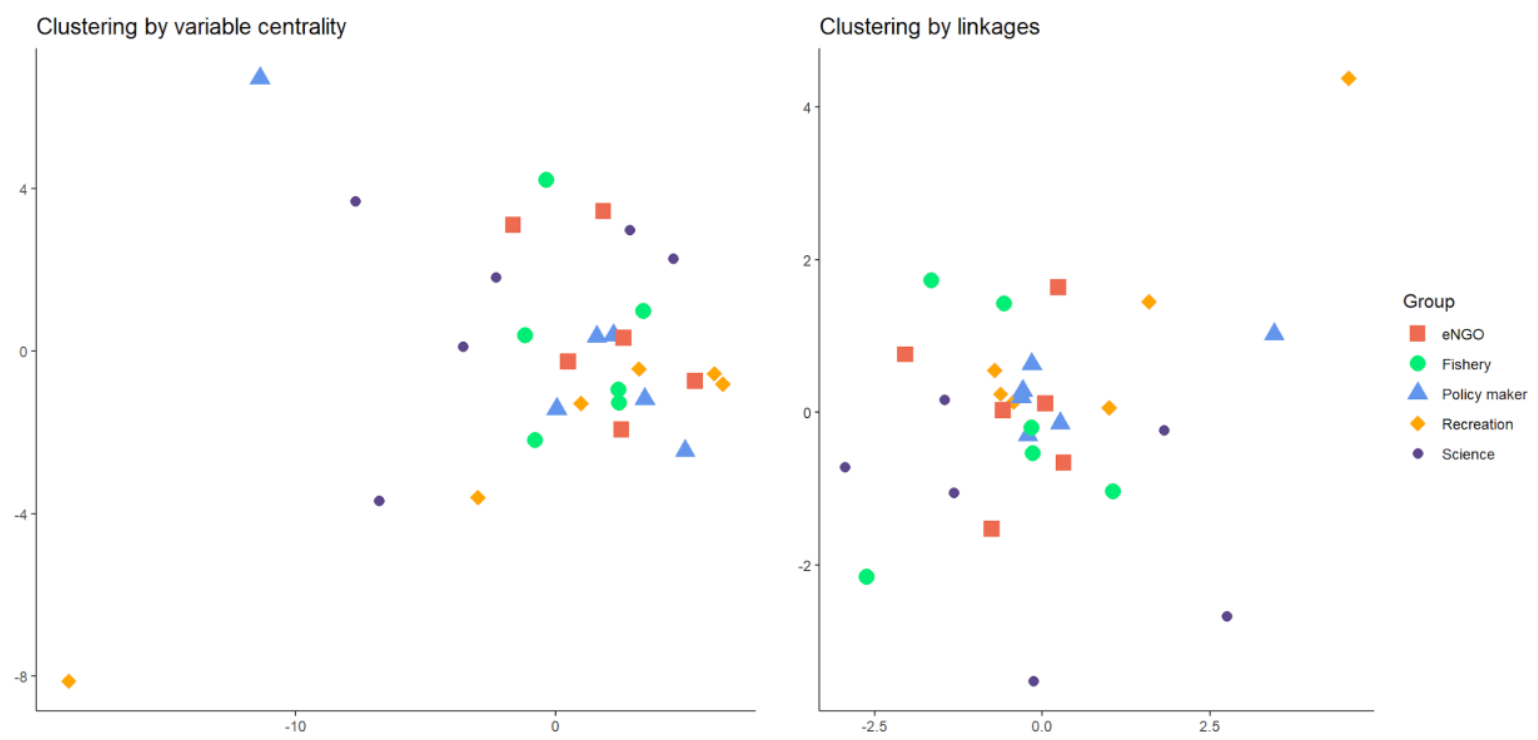

Figure 4: Ordination of respondents by variable centrality (i.e. how central is each of the variables in each map; left) and by the linkages between the variables (i.e. which variables have links between them, and how similar are the link strengths; right).
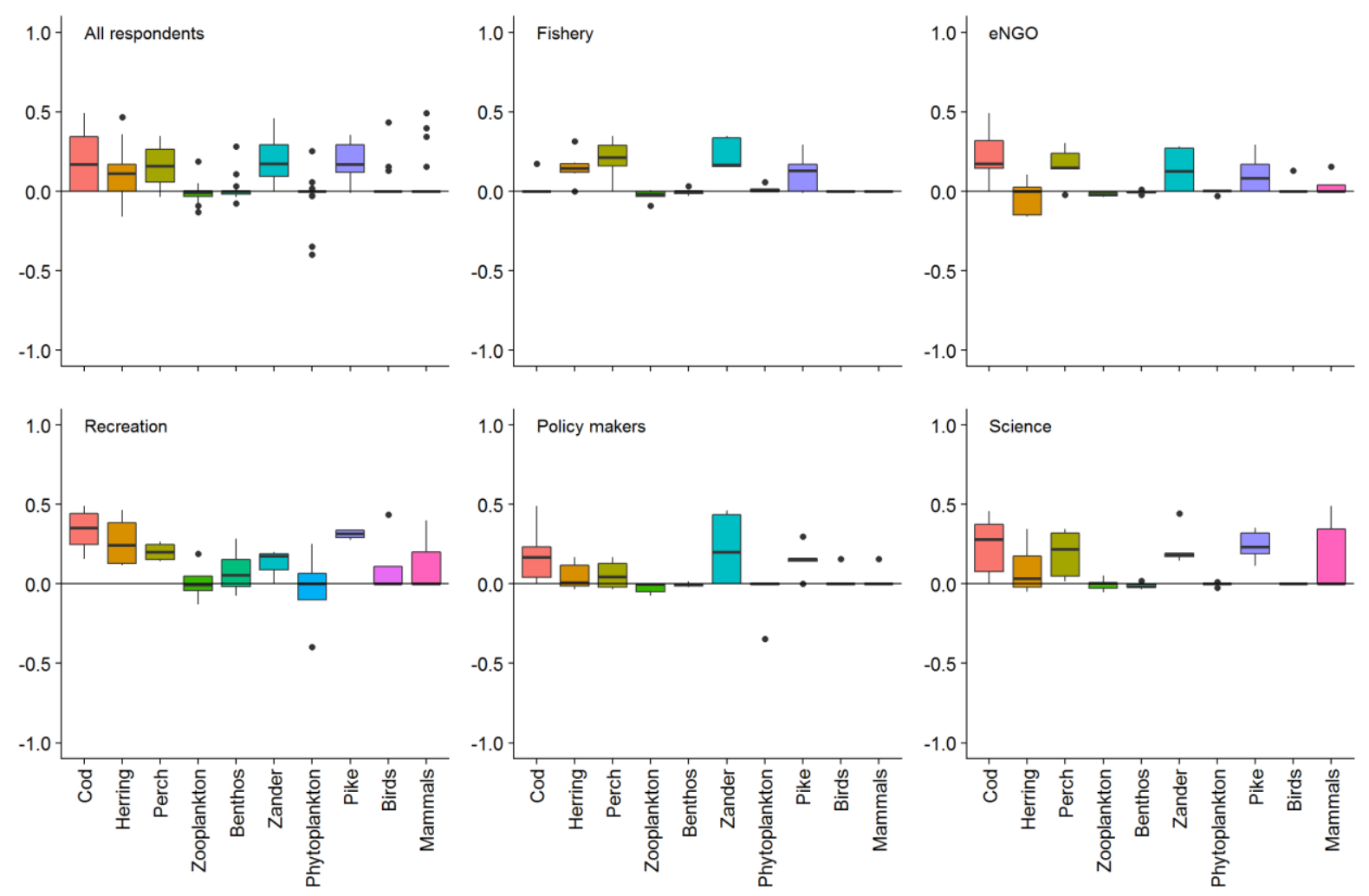

Figure 5: The changes of the 10 most central ecosystem components (in that order, see Figure 2) in the decreased fishing scenario, compared to the "no changes" scenario of each map. Values above zero indicate that this ecosystem component is expected to increase in this scenario; below zero, to decrease. 

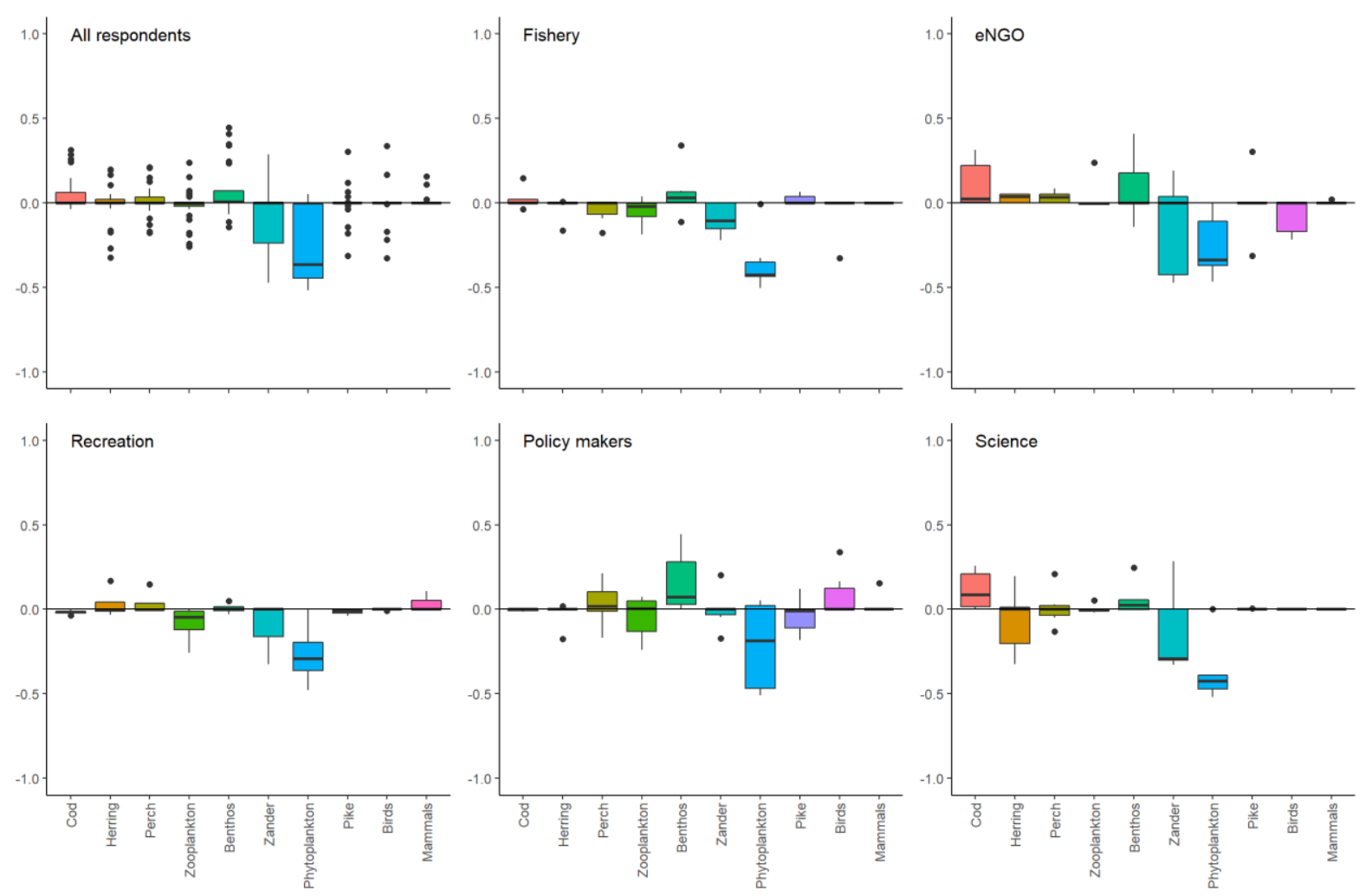

Figure 6: The changes of the 10 most central ecosystem components (in that order, see Figure 2) in the decreased eutrophication scenario, compared to the "no changes" scenario of each map. Values above zero indicate that this ecosystem component is expected to increase in this scenario; below zero, to decrease. All the scenario figures are plotted in the R code available at https://github.com/luusitalo/FCM_AS.

\section{Discussion}

Our results demonstrate that all stakeholder groups have a quite similar understanding of the Archipelago sea food web. There were no statistically significant differences in the number of variables or the density of the interactions (Figure 2), and the different stakeholder groups were not clustered but were clearly mixed (Figure 4). While there were individual variations in the models, this variation did not reveal division lines between the stakeholder groups (except differences in variation in the centrality and connection density, discussed below), despite the conflicts around ecosystem management in the area (e.g. Hansson et al. 2018a, 2018b; Heikinheimo et al., 2018). This information is highly useful background knowledge for organizing discussions about the conflicts (Fisher \& Sablan, 2017). The rather similar understanding of the food web structure may reflect the fact that many of the respondents, regardless of their stakeholder group, have training and professional experience in aquatic ecology, and those who haven't are likely to have read a lot about the topic as well. The similarity of these models means that they can be combined (Gray et al., 2012) to form a conceptual model on the food web interactions that is likely to be well-accepted by all the stakeholders in the area, which can be useful in future stakeholder consultations regarding the management options in the area. This combined model could be used as the basis of a face-to-face consensus model development process (Hobbs et al., 2002; Vasslides \& Jensen, 2016).

The differences between the number of variables and the connection density of the models were not statistically significant in these small data, however the variability between individuals was quite high (Figure 2). Variability in the number of variables was high in two groups: scientists and recreational users. The scientists' field likely impacted on the resolution of the map and recreational users tended to concentrate on variables they knew most about and found interesting, while the other groups possibly focused on the variables they considered most important. The 20-variable restriction can also have affected this result somewhat, since 4 of the maps had more than 19 variables; these respondents might have included more without the restriction. The restriction may have also guided the other respondents to include more variables than they would have done otherwise. 
The connection density must be evaluated together with the number of variables within each map. The group with the highest average number of variables, Fishery, was also that of lowest link density - however note that the link density is relative to the exponential of the number of variables (i.e. the maximum possible number of links there could be in the model). Therefore, essentially the same ecological interactions can be represented in one model as fewer variables and relatively higher number of links between them (higher abstraction/ simplification, Figure 7a), and in another model by paths including more variables and therefore relatively fewer links between them (Figure $7 \mathrm{~b}$ ). Therefore, link density and the number of variables should be used together when evaluating model complexity.

a)

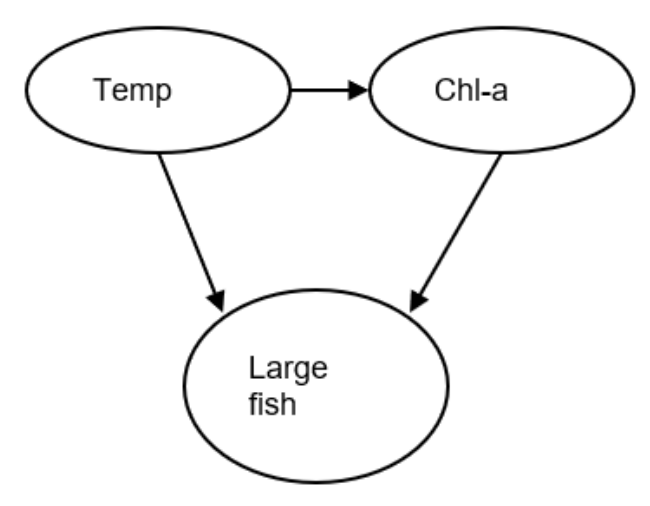

b)

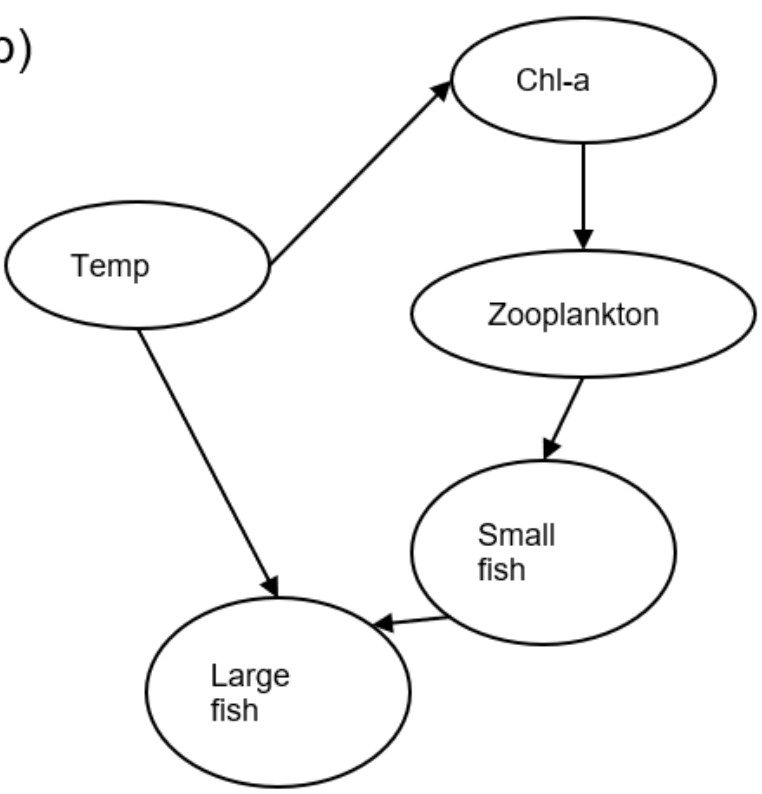

Figure 7: An example of link density calculation. a) Model has 3 variables and its links density is 0.5 (3 links out of 6 possible). b) Model has 5 variables and its links density is 0.25 ( 5 links out of 20 possible).

The variables that had the highest centrality values varied slightly between stakeholder groups (Figure 3) but there were no major deviations between groups. Zander was considered more central by scientists and fishers than by the other groups. Science and recreational groups considered fishing more central than eutrophication, while for the other groups this order was reversed. The science and recreational groups varied the most from the other groups (Figure 3). This may be explained by the length of professional experience with the system: most of the policy maker, eNGO, and fishery respondents have graduate level training on aquatic ecology, while the recreation respondents came from a more variable educational background. The science respondents, on the other hand, work on a daily basis on some aspect of the Baltic Sea ecosystem, and may perceive as central some components that others (other scientists and actors) don't. The variables that were the most central across all models were the ones given to the respondents in the proposed components list (Table 1, Figure 3). This may be partly an artefact caused by the respondents being biased towards the variables that had been presented to them; but on the other hand, these are some of the key variables in the system so respondents might have included many of those even without the list. Cod's centrality in most models was, also probably due to the advice that they should keep cod central in the model.

The provision of the indicative list of ecosystem components was likely to direct the model building of the respondents, and their individual models might have been more variable without this guidance (Fairweather, 2010; Markóczy \& Goldberg, 1995; Meliadou et al. 2012). The list also helped to bring the models to approximately the same level of abstraction; in related workshops we observed that without this kind of guidance, some of the models might focus on the high level policy and governance questions, or only on a smaller part of the food web such as the different fish species. The harmonization provided by the example and the proposed components allowed us to cluster, simulate, and compare the models in a meaningful way. As the aim of this work was to do quantitative analysis, this guidance was justified to reach this goal (Özesmi \& Özesmi, 2004). More in-depth, qualitative analysis of stakeholder mental maps might, on the other hand, benefit from a more flexible approach, such as letting them draw a mental map first without the framing and then revise it to 
align better with the intended framing. However, multiple respondents commented that they found it surprisingly difficult to start drawing the model on a blank sheet. Not having a list of components as a starting point might make the task even more intimidating and might lead to difficulties in gaining the models.

The pressures and state changes (fishing, eutrophication, oxygen, temperature, salinity) also featured on the most central variables list, as the respondents were specifically requested to include them in their models. Some respondents also commented during the model drawing process, that they feel that they have a clearer picture of the effects of these factors on the ecosystem than they do have of the intra-food web relationships. This may have boosted their centrality to some extent, as well. This observation indicates that science communication about the effects of pressures may have been more effective than that about the food web complexity and interactions. FCMs may serve as one tool to illustrate the cascading impacts of pressures in the food webs, and the importance of food web interactions in this process.

The scenario runs (Figures 5-6) further strengthen the conclusion that there are no major differences between the stakeholder groups in how they view the Archipelago Sea food web. While there were differences between the strengths of the expected impacts of the scenarios (decreased eutrophication and decreased fishing), the big picture is remarkably similar across all stakeholder groups. One of the most contradictory outcomes of these simulations was that in the decreased eutrophication scenario, the policy maker group expected birds to increase, while the eNGO group expected them to decrease. The other groups didn't expect any changes to the bird group in this scenario. This discrepancy may be due to the bird group including species with very different strategies and characteristics, so the response may differ according to which of these groups were in the respondents' minds.

The results demonstrate that there is less divergence than expected in the views of the Archipelago sea food web structure held by the different stakeholder groups; thus in principle these views should not lay ground for continuing debate over ecosystem function, often presented as being at the core of the debate (e.g. Hansson et al. 2018a, 2018b; Heikinheimo et al., 2018). As conflict remains however, the contradiction between the lack of disagreement found in the FCMs and the positions taken by the different groups raises questions around the true foundations of the conflict. Firstly, it would be interesting to examine how the stakeholder groups perceive the implications of certain cause-effect relationships between variables. For instance, different views on overall population dynamics can lead to differences in perceptions of how an increase in predation on fish impacts fisheries' catches (and the acceptability of such an impact). There may also be different views on the effect of animal behaviour and it's broader system-scale effects - e.g. predator presence on fish behavior, which may have a remarkable impact on fishing catch sizes, especially on a local level, in addition to any impact on stock levels due to the consumption of fish by predators.

FCM have previously been used to study differences of opinion amongst stakeholder groups in other topic areas. Christen et al. (2015) conducted a FCM exercise to study whether the approach can help identify a lack of alignment in perceptions of different stakeholder groups in agricultural policy in Scotland. They found considerable differences in the perceptions of farmers and non-farmers, and concluded that FCM can help to disentangle these differences. Özesmi and Özesmi (2003) conducted a FCM elicitation process for stakeholders from six different groups for a freshwater ecosystem management plan in Turkey. They found that the exercise was useful in finding the similarities and differences in the stakeholders' views, and to facilitate discussion.

The model elicitation method used here is a direct elicitation method (Jones et al., 2011), meaning that the respondents are asked to form a representation of their mental model, e.g. by drawing a diagram, possibly aided with a set of provided concepts (Jones et al., 2011). An alternative approach is indirect elicitation, where a representation of a mental map is drawn by the analyst based on interviews or written text (Jones et al., 2011). Unlike the indirect method, the direct method gives the respondents the possibility to review the representation of their mental model (Jones et al., 2011). LaMere et al. (2020) however note that these models may also be simpler than what can be deduced from verbal descriptions, and propose a new methodology, combining direct and indirect elicitation techniques, to increase the model richness while retaining their integrity. This method might provide better representations of the stakeholders' mental maps than the approach taken here and therefore shed additional light to the sources of conflicts in this area.

Stakeholder elicitation has also been used as the basis of building Bayesian Network (BN) models (e.g. Haapasaari et al., 2012; Salliou et al., 2017). BNs are rather sophisticated models, allowing many types of 
analysis, including the kind of analyses performed on the FCMs here (e.g. Uusitalo, 2007), but building a BN requires much higher time investment from the stakeholders (Salliou et al., 2017). In contrast, Fuzzy cognitive mapping serves as a relatively approachable tool for elicitation of stakeholder views of an ecosystem's functioning, and can thus help to pinpoint and disentangle the root causes of disagreements regarding the environmental management. While some of the participants noted that it was surprisingly challenging to start the mapping exercise, they were nevertheless able to produce coherent maps in a short time, as was observed also by van Vliet et al. (2010).

To the best of our knowledge, this is the first attempt to address the Archipelago Sea management conflict with transdisciplinary modelling. Compared to the straightforwardness of the mapping, the extent of analytical tools available in the FCM framework to explore and simulate these models is impressive, and may bring valuable insights. However, in disputed management conditions, a modelling approach such as this is only the first step to disentangle the problem. These results can serve as the starting point for additional in-depth interviews with the stakeholders, which would provide more information about the root causes of the disagreement, for example perceived implications of the causal relationships between the variables.

\section{Acknowledgements}

This work was funded through the project Blue growth boundaries in novel Baltic food webs (BONUS BLUEWEBS), which has received funding from BONUS (Art 185), funded jointly by the EU and the Academy of Finland. We wish to thank Bas Bolman and two anonymous reviewers for their constructive comments on the manuscript; they improved the manuscript considerably.

\section{References}

BACC II Author Team. 2015. Second Assessment of Climate Change for the Baltic Sea Basin. Regional climate studies. 501 pp. https://doi.org/10.1007/978-3-319-16006-1

Chan, K.M.A., Satterfield, T., Goldstein, J., 2012. Rethinking ecosystem services to better address and navigate cultural values. Ecol. Econ. 74, 8-18. https://doi.org/10.1016/j.ecolecon.2011.11.011

Christen, B., Kjeldsen, C., Dalgaard, T., Martin-Ortega, J., 2015. Can fuzzy cognitive mapping help in agricultural policy design and communication? Land Use Policy 45, 64-75. https://doi.org/10.1016/j.landusepol.2015.01.001

Fairweather, J., 2010. Farmer models of socio-ecologic systems: Application of causal mapping across multiple locations. Ecol. Model. 221, 555-562. https://doi.org/10.1016/j.ecolmodel.2009.10.026

Fisher, M. \& Sablan, T. 2017. Evaluating environmental conflict resolution: Practitioners, projects, and the movement. Conflict Resolution Quarterly. 2018;36:7-19.

Game, E.T., Bremer, L.L., Calvache, A., Moreno, P.H., Vargas, A., Rivera, B., Rodriguez, L.M., 2018. Fuzzy Models to Inform Social and Environmental Indicator Selection for Conservation Impact Monitoring. Conserv. Lett. 11, e12338. https://doi.org/10.1111/conl.12338

Giabbanelli, P.J., Gray, S.A., Aminpour, P., 2017. Combining fuzzy cognitive maps with agent-based modeling: Frameworks and pitfalls of a powerful hybrid modeling approach to understand human-environment interactions. Environ. Model. Softw. 95, 320-325. https://doi.org/10.1016/j.envsoft.2017.06.040

Gray, S., Chan, A., Clark, D., Jordan, R., 2012. Modeling the integration of stakeholder knowledge in social-ecological decision-making: benefits and limitations to knowledge diversity. Ecological Modelling, 229, pp.88-96. Haapasaari, P., S. Mäntyniemi, and S. Kuikka. 2012. Baltic herring fisheries management: stakeholder views to frame the problem. Ecology and Society 17(3): 36. http://dx.doi.org/10.5751/ES-04907-170336

Hansson, S., Bergström, U., Bonsdorff, E., Härkönen, T., Jepsen, N., Kautsky, L., Lundström, K., Lunneryd, S.-G., Ovegård, M., Salmi, J., Sendek, D., Vetemaa, M., 2018a. Competition for the fish - fish extraction from the Baltic Sea by humans, aquatic mammals, and birds. ICES J. Mar. Sci. 75, 999-1008. https://doi.org/10.1093/icesjms/fsx207

Hansson, S., Kautsky, L., Bergström, U., Bonsdorff, E., Jepsen, N., Lundström, K., Lunneryd, S.-G., Ovegård, M., Salmi, J., Sendek, D., Vetemaa, M., 2018b. Response to comments by Heikinheimo et al. (in press) on Hansson et al. (2018): competition for the fish-fish extraction from the Baltic Sea by humans, aquatic mammals, and birds. ICES J. Mar. Sci. 75, 1837-1839. https://doi.org/10.1093/icesjms/fsy087

Harding, K.C., Härkönen, T.J., 1999. Development in the Baltic Grey Seal (Halichoerus grypus) and Ringed Seal (Phoca hispida) Populations during the 20th Century. Ambio 28, 619-627.

Heikinheimo, O., Lehtonen, H., Lehikoinen, A., 2018. Comment to Hansson, S. et al. (2017): "Competition for the fish - fish extraction from the Baltic Sea by humans, aquatic mammals, and birds", with special reference to cormorants, perch, and pikeperch. ICES J. Mar. Sci. 75, 1832-1836. https://doi.org/10.1093/icesjms/fsy054 
Hobbs, B.F., Ludsin, S.A., Knight, R.L., Ryan, P.A., Biberhofer, J., Ciborowski, J.J.H., 2002. Fuzzy Cognitive Mapping as a Tool to Define Management Objectives for Complex Ecosystems. Ecol. Appl. 12, 1548-1565. https://doi.org/10.1890/1051-0761(2002)012[1548:FCMAAT]2.0.CO;2

Jetter, A.J., Kok, K., 2014. Fuzzy Cognitive Maps for futures studies-A methodological assessment of concepts and methods. Futures 61, 45-57. https://doi.org/10.1016/j.futures.2014.05.002

Jones, N. A., H. Ross, T. Lynam, P. Perez, Leitch, A. 2011. Mental models: an interdisciplinary synthesis of theory and methods. Ecology and Society 16(1):46. http://www.ecologyandsociety.org/vol16/iss1/art46

Kauhala, K., Korpinen, S., Lehtiniemi, M., Raitaniemi, J., 2019. Reproductive rate of a top predator, the grey seal, as an indicator of the changes in the Baltic food web. Ecol. Indic. 102, 693-703. https://doi.org/10.1016/j.ecolind.2019.03.022

Kontogianni, A.D., Papageorgiou, E.I., Tourkolias, C., 2012. How do you perceive environmental change? Fuzzy Cognitive Mapping informing stakeholder analysis for environmental policy making and non-market valuation. Appl. Soft Comput., Theoretical issues and advanced applications on Fuzzy Cognitive Maps 12, 3725-3735. https://doi.org/10.1016/j.asoc.2012.05.003

Kosko, B., 1986. Fuzzy cognitive maps. Int. J. Man-Mach. Stud. 24, 65-75. https://doi.org/10.1016/S0020-7373(86)80040-2

Kraufvelin, P., Pekcan-Hekim, Z., Bergström, U., Florin, A.-B., Lehikoinen, A., Mattila, J., Arula, T., Briekmane, L., Brown, E.J., Celmer, Z., Dainys, J., Jokinen, H., Kääriä, P., Kallasvuo, M., Lappalainen, A., Lozys, L., Möller, P., Orio, A., Rohtla, M., Saks, L., Snickars, M., Støttrup, J., Sundblad, G., Taal, I., Ustups, D., Verliin, A., Vetemaa, M., Winkler, H., Wozniczka, A., Olsson, J., 2018. Essential coastal habitats for fish in the Baltic Sea. Estuar. Coast. Shelf Sci. 204, 14-30. https://doi.org/10.1016/j.ecss.2018.02.014

LaMere K., Mäntyniemi S., Vanhatalo J., Haapasaari, P., 2020. Making the most of mental models: Advancing the methodology for mental model elicitation and documentation with expert stakeholders. Environmental Modelling and Software 124, 104589. https://doi.org/10.1016/j.envsoft.2019.104589

Leppäkoski, E., Helminen, H., Hänninen, J., Tallqvist, M., 1999. Aquatic biodiversity under anthropogenic stress: an insight from the Archipelago Sea (SW Finland). Biodivers. Conserv. 8, 55-70. https://doi.org/10.1023/A:1008805007339

Markóczy, L., Goldberg, J., 1995. A method for eliciting and comparing causal maps. J. Manag. 21, 305-333. https://doi.org/10.1016/0149-2063(95)90060-8

Meliadou, A., Santoro, F., Nader, M.R., Dagher, M.A., Al Indary, S. and Salloum, B.A., 2012. Prioritising coastal zone management issues through fuzzy cognitive mapping approach. Journal of environmental management, 97, pp.5668.

Özesmi, U., Özesmi, S.L., 2004. Ecological models based on people's knowledge: a multi-step fuzzy cognitive mapping approach. Ecol. Model. 176, 43-64. https://doi.org/10.1016/j.ecolmodel.2003.10.027

Özesmi, U., Özesmi, S.L., 2003. A Participatory Approach to Ecosystem Conservation: Fuzzy Cognitive Maps and Stakeholder Group Analysis in Uluabat Lake, Turkey. Environ. Manage. 31, 0518-0531. https://doi.org/10.1007/s00267-0022841-1

Pacilly, F.C.A., Groot, J.C.J., Hofstede, G.J., Schaap, B.F., van Bueren, E.T.L., 2016. Analysing potato late blight control as a social-ecological system using fuzzy cognitive mapping. Agron. Sustain. Dev. 36, 35. https://doi.org/10.1007/s13593016-0370-1

Pahl-Wostl, C., Craps, M., Dewulf, A., Mostert, E., Tabara, D., Taillieu, T., 2007. Social Learning and Water Resources Management. Ecol. Soc. 12. https://doi.org/10.5751/ES-02037-120205

$R$ Core Team, 2018. R: A language and environment for statistical computing.

Salliou, N., Barnaud, C., Vialatte, A., Monteil, C. 2017. A participatory Bayesian Belief Network approach to explore ambiguity among stakeholders about socio-ecological systems. Environmental Modelling \& Software 96: 199209.https://doi.org/10.1016/j.envsoft.2017.06.050.

Salmi, J.A., Auvinen, H., Raitaniemi, J., Kurkilahti, M., Lilja, J., Maikola, R., 2015. Perch (Perca fluviatilis) and pikeperch (Sander lucioperca) in the diet of the great cormorant (Phalacrocorax carbo) and effects on catches in the Archipelago Sea, Southwest coast of Finland. Fish. Res. 164, 26-34. https://doi.org/10.1016/j.fishres.2014.10.011

Sluis, T. van der, Arts, B., Kok, K., Bogers, M., Busck, A.G., Sepp, K., Loupa-Ramos, I., Pavlis, V., Geamana, N., Crouzat, E., 2019. Drivers of European landscape change: stakeholders' perspectives through Fuzzy Cognitive Mapping. Landsc. Res. 44, 458-476. https://doi.org/10.1080/01426397.2018.1446074

Solana-Gutiérrez, J., Rincón, G., Alonso, C., García-de-Jalón, D., 2017. Using fuzzy cognitive maps for predicting river management responses: A case study of the Esla River basin, Spain. Ecol. Model. 360, 260-269. https://doi.org/10.1016/j.ecolmodel.2017.07.010

Stier, A.C., Samhouri, J.F., Gray, S., Martone, R.G., Mach, M.E., Halpern, B.S., Kappel, C.V., Scarborough, C., Levin, P.S., 2017. Integrating Expert Perceptions into Food Web Conservation and Management. Conserv. Lett. 10, 67-76. https://doi.org/10.1111/conl.12245

Taber, W.R., 1991. Knowledge processing with fuzzy cognitive maps. Expert Syst. Appl. 2, 83-87.

Uusitalo, L. 2007. Advantages and challenges of Bayesian networks in environmental modelling. Ecological Modelling 203:312-318.van Vliet, M., Kok, K., Veldkamp, T., 2010. Linking stakeholders and modellers in scenario studies: The use of Fuzzy Cognitive Maps as a communication and learning tool. Futures 42, 1-14. https://doi.org/10.1016/j.futures.2009.08.005 
Vasslides, J.M., Jensen, O.P., 2016. Fuzzy cognitive mapping in support of integrated ecosystem assessments: Developing a shared conceptual model among stakeholders. J. Environ. Manage. 166, 348-356. https://doi.org/10.1016/j.jenvman.2015.10.038

Venables, W.N., Ripley, B.D., 2002. Modern Applied Statistics with S, Fourth Ed. Springer, New York.

Viirret, E., Raatikainen, K.J., Fagerholm, N., Käyhkö, N., Vihervaara, P., 2019. Ecosystem Services at the Archipelago Sea Biosphere Reserve in Finland: A Visitor Perspective. Sustainability 11, 421. https://doi.org/10.3390/su11020421

Virtanen, E.A., Viitasalo, M., Lappalainen, J., Moilanen, A., 2018. Evaluation, Gap Analysis, and Potential Expansion of the Finnish Marine Protected Area Network. Front. Mar. Sci. 5. https://doi.org/10.3389/fmars.2018.00402 